\title{
A Silent Synapse-Based Mechanism for Cocaine-Induced Locomotor Sensitization
}

\author{
Travis E. Brown, ${ }^{1 \star}$ Brian R. Lee, ${ }^{1 *}$ Ping Mu, ${ }^{1}$ Deveroux Ferguson, ${ }^{2}$ David Dietz, ${ }^{2}$ Yoshinori N. Ohnishi, ${ }^{2}$ Ying Lin, ${ }^{3}$ \\ Anna Suska, ${ }^{4,5}$ Masago Ishikawa, ${ }^{1}$ Yanhua H. Huang, ${ }^{1}$ Haowei Shen, ${ }^{6}$ Peter W. Kalivas, ${ }^{6}$ Barbara A. Sorg, ${ }^{1}$ \\ R. Suzanne Zukin, ${ }^{3}$ Eric J. Nestler, ${ }^{2}$ Yan Dong, ${ }^{1}$ and Oliver M. Schlüter ${ }^{4,5}$ \\ ${ }^{1}$ Program in Neuroscience, Washington State University, Pullman, Washington 99164-6520, ${ }^{2}$ Fishberg Department of Neuroscience, Mount Sinai School of \\ Medicine, New York, New York 10029, ${ }^{3}$ Dominick P. Purpura Department of Neuroscience, Albert Einstein College of Medicine, New York NY 10460, \\ ${ }^{4}$ Molecular Neurobiology, European Neuroscience Institute, 37077 Göttingen, Germany, ${ }^{5}$ Molecular Physiology of the Brain, Göttingen Graduate School for \\ Neurosciences and Molecular Biosciences, 37077 Göttingen, Germany, ${ }^{6}$ Department of Neuroscience, Medical University of South Carolina, Charleston, \\ South Carolina 29425
}

Locomotor sensitization is a common and robust behavioral alteration in rodents whereby following exposure to abused drugs such as cocaine, the animal becomes significantly more hyperactive in response to an acute drug challenge. Here, we further analyzed the role of cocaine-induced silent synapses in the nucleus accumbens (NAc) shell and their contribution to the development of locomotor sensitization. Using a combination of viral vector-mediated genetic manipulations, biochemistry, and electrophysiology in a locomotor sensitization paradigm with repeated, daily, noncontingent cocaine $(15 \mathrm{mg} / \mathrm{kg})$ injections, we show that dominant-negative cAMP-element binding protein (CREB) prevents cocaine-induced generation of silent synapses of young ( $30 \mathrm{~d}$ old) rats, whereas constitutively active CREB is sufficient to increase the number of NR2B-containing NMDA receptors (NMDARs) at synapses and to generate silent synapses. We further show that occupancy of CREB at the NR2B promoter increases and is causally related to the increase in synaptic NR2B levels. Blockade of NR2B-containing NMDARs by administration of the NR2B-selective antagonist Ro256981 directly into the NAc, under conditions that inhibit cocaine-induced silent synapses, prevents the development of cocaine-elicited locomotor sensitization. Our data are consistent with a cellular cascade whereby cocaine-induced activation of CREB promotes CREB-dependent transcription of NR2B and synaptic incorporation of NR2B-containing NMDARs, which generates new silent synapses within the NAc. We propose that cocaineinduced activation of CREB and generation of new silent synapses may serve as key cellular events mediating cocaine-induced locomotor sensitization. These findings provide a novel cellular mechanism that may contribute to cocaine-induced behavioral alterations.

\section{Introduction}

In animal models, a hallmark feature associated with chronic exposure to drugs of abuse is locomotor sensitization (Robinson and Berridge, 2000). It has been hypothesized that the molecular and cellular mechanisms mediating locomotor sensitization also contribute to drug-induced pathophysiological emotional and motivational states characteristic of addiction (Robinson and Berridge, 2000, 2001, 2008). Thus, elucidating the molecular and

\footnotetext{
Received Jan. 3, 2011; revised Feb. 9, 2011; accepted Feb. 11, 2011.

Author contributions: T.E.B., B.R.L., P.M., D.F., D.M.D., Y.N.O., Y.L., A.S., M.I., Y.H.H., H.W.S., P.K., B.S., R.S.Z., E.N., Y.D., and O.M.S. designed research; T.E.B., B.R.L., P.M., D.F., D.M.D., Y.N.O., Y.L., A.S., M.I., Y.H.H., and H.W.S. performed research; T.E.B., B.R.L., P.M., D.F., D.M.D., Y.N.O., Y.L., A.S., M.I., Y.H.H., H.W.S., Y.D., and O.M.S. analyzed data; Y.H.H., P.K., B.S., R.S.Z., E.N., Y.D., and O.M.S. wrote the paper.

*T.E.B. and B.R.L. contributed equally to this work.

This work was supported by the Humboldt Foundation (to Y.D.), the Alcohol and Drug Abuse Research Program of Washington State, the Hope Foundation for Depression Research, and by National Institutes of Health (NIH) Grants DA023206, DA028020, DA01433, and DA08227. Cocaine was supplied in part by the Drug Supply Program of NIH National Institute on Drug Abuse. The European Neuroscience Institute is jointly funded by the University Medicine Göttingen and the Max Planck Society.

Correspondence should be addressed to either Dr. Yan Dong, Wegner 205, P.0. Box 646520, Washington State University, Pullman, WA 99164-6520, E-mail: yan_dong@wsu.edu; or Dr. Oliver M. Schlüter, European Neuroscience Institute, Grisebachstrasse 5, 37077 Göttingen, Germany, E-mail: oschlue@gwdg.de.

DOI:10.1523/JNEUROSCI.0016-11.2011

Copyright $\odot 2011$ the authors $\quad 0270-6474 / 11 / 318163-12 \$ 15.00 / 0$
}

cellular mechanisms underlying the development of this druginduced psychomotor response would provide significant insight into the neural bases for drug addiction.

The forebrain region nucleus accumbens (NAc) is critically involved in the development of a variety of addiction-related behavioral alterations (for review, see Koob and Volkow, 2010). A prevailing view had been that induction of locomotor sensitization occurs in the ventral tegmental area, whereas expression of locomotor sensitization is mediated by the NAc (Wolf, 1998; Kalivas, 2004; Kauer and Malenka, 2007; Thomas et al., 2008). However, several studies involving site-specific brain-lesioning, pharmacology, or genetic manipulations consistently demonstrate that the NAc, especially glutamatergic synaptic transmission within the NAc, is essential for both the induction and expression phases of cocaine-induced locomotor sensitization (Kafetzopoulos, 1986; Hooks et al., 1993; Vanderschuren and Kalivas, 2000; Todtenkopf et al., 2002; Kalivas et al., 2009; Maze et al., 2010; Wolf and Ferrario, 2010).

Exposure to cocaine drives insertion of NR2B-containing NMDA receptors (NMDARs) and generates silent synapses in the NAc, with a time course that correlates with the development of locomotor sensitization (Huang et al., 2009). Silent glutamater- 
gic synapses, which express functional NMDAR-mediated currents in the absence of AMPA receptor (AMPAR)-mediated currents, are thought to possess an increased capacity to undergo strengthening of synaptic transmission (Isaac et al., 1995; Liao et al., 1999; Pickard et al., 2000; Groc et al., 2006). Our previous findings demonstrate that cocaine-induced synaptic incorporation of NR2B-containing receptors generates silent synapses in the NAc shell (Huang et al., 2009). These newly generated silent synapses may prime the neuronal circuitry of the animal to engage new connections and support NAc-based long-lasting cellular and behavioral adaptations.

This study was aimed to identify the key molecular processes that mediate cocaine-induced generation of silent synapses and, by targeting the identified key molecular components, to examine a possible causal relation of silent synapses to cocaine-induced locomotor sensitization. The transcription factor cAMP-response element binding protein (CREB) is activated within minutes upon cocaine exposure in vivo (Brami-Cherrier et al., 2005; Mattson et al., 2005; Hyman et al., 2006). Upon activation, CREB promotes gene transcription of NR2B (Rani et al., 2005), and CREB generates silent synapses in hippocampal neurons (Marie et al., 2005). Here, we show that CREB is critical to cocaineinduced generation of silent synapses in NAc neurons by activation of NR2B gene transcription. Furthermore, intra-NAc inhibition of NR2B-containing NMDARs, which disables silent synapses, prevents the development, but not the expression, of cocaine-induced locomotor sensitization. These findings suggest a potential role for cocaine-induced silent synapses as a structural correlate for cocaine-induced behavioral sensitization.

\section{Materials and Methods}

Animal use, intraperitoneal injection of cocaine, and cell selection. Male Sprague Dawley rats ( $\sim 30 \mathrm{~d}$ old) were used. Before drug administration or molecular manipulation, rats were allowed to acclimate to their home cages for $>5 \mathrm{~d}$. Two procedures of repeated cocaine administration used in this study were similar to earlier studies (Zhang et al., 2003; Dong et al., 2006). In procedure 1 (referred to as the $5 \mathrm{~d}$ procedure), rats received daily injections of either $(-)$ cocaine $\mathrm{HCl}(15 \mathrm{mg} / \mathrm{kg}$, i.p. $)$ or the same volume of saline for $5 \mathrm{~d}$. In procedure 2 (referred to as the $2.5 \mathrm{~d}$ procedure), rats received one injection of cocaine $(15 \mathrm{mg} / \mathrm{kg})$ on day 1 in the afternoon, and two daily injections ( $8 \mathrm{~h}$ apart) of cocaine $(15 \mathrm{mg} / \mathrm{kg}$ ) for the following $2 \mathrm{~d}$. The $2.5 \mathrm{~d}$ procedure was only used in experiments involving viral expression, in which the in vivo viral injection was performed on day 1 in the morning. Cocaine injections for electrophysiological and biochemical experiments were performed in a novel cage (15 $\mathrm{min}$ ), the same size as the home cage, walled with white plastic plate, and floored with white-diamond soft bedding (Harlan). Cocaine-treated rats from both procedures were then used for electrophysiological recordings and biochemical assays $24-48 \mathrm{~h}$ following the last injection. Electrophysiological recordings were preferentially made from the medium spiny neurons (MSNs) located in the ventral-medial subregion of the NAc shell, which could be identified by anatomical landmarks.

All procedures were performed by strictly following the standard procedures approved by the Institutional Animal Care and Use Committee at Washington State University.

Virus preparation and in vivo delivery. Sindbis virus ( $\mathrm{pSINrep} 2 \mathrm{~S}^{726}$ ), expressing constitutively active CREB (caCREB) and a dominantnegative form of CREB (dnCREB) upstream of an IRES-GFP sequence, was produced similar to published protocols (Marie et al., 2005; Dong et al., 2006; Huang et al., 2007) except that the toxicity was further minimized by using a new sindbis virus-based vector, pSINrep (nsP2S ${ }^{726}$ ) and its corresponding optimized helper vector DH-BB (tRNA/TE12) (Kim et al., 2004). Some similar results were obtained with herpes simplex viruses, expressing the same constructs.

To deliver the viruses into the NAc shell, we used stereotaxic injection. Briefly, we first anesthetized the rats with a ketamine/xylazine mixture and installed a guide cannula into the NAc shell (in mm: anterior, 1.5; lateral, 0.6; dorsal, 6.5). One week later, after rats had recovered from surgery, we injected viruses into the NAc shell through the guide cannulae; concentrated viral solutions $(1 \mu \mathrm{l} / \mathrm{side})$ were infused into the NAc shell through a pump at a flow rate of $0.2 \mu \mathrm{l} / \mathrm{min}$. The injection cannula was then slowly withdrawn and the rats were placed on the warmed heating pad for postsurgical recovery. Because the whole injection process took $<10$ min with minimal disturbance, we only briefly anesthetized the rats with isoflurane for this purpose. After waking up, rats were transferred to regular housing cages. We identified the infected neurons in living slices by the GFP signal using epifluorescence microscopy.

The expression efficacy varied between cells and we chose to record cells with only weak GFP-signals with the assumption that relatively lower expression efficacy exerted less nonspecific effects. All virally infected cells were recorded on day 3 after the injection day except for the caCREB-expressing cells, for which the recording was performed $24 \mathrm{~h}$ after injection.

We validated the new virus by recording from uninfected (uninf) NAc neurons and neurons expressing GFP alone. Neither the break-in resting membrane potential (in $\mathrm{mV}$ : uninf, $-81.7 \pm 0.8, n=19$; GFP, $-80.8 \pm$ $0.9, n=13, p=0.47$ ) nor the break-in membrane resistance (in $\mathrm{M} \Omega$ : uninf, 446.6 $\pm 14, n=20$; GFP, $438.9 \pm 15, n=12$ ) was affected by the expression of pSINrep (nsP2S-GFP). Furthermore, we compared AMPAR/NMDAR ratio, a parameter that reflects the basic property of excitatory synapses, between uninfected NAc neurons and GFPexpressing neurons. Again, no difference was observed (uninf, $1.2 \pm 0.1$, $n=25$; GFP, $1.3 \pm 0.1, n=6, p>0.1$; AMPAR EPSCs were measured at $-80 \mathrm{mV}$ and NMDAR EPSCS were measured at $+40 \mathrm{mV})$. When performing virus-related experiments, we always included uninfected and GFP-expressing cells as controls.

To study the involvement of CREB in cocaine induction of dendritic spines, we used herpes simplex virus vectors based on published protocols (Carlezon et al., 2005). dnCREB (S133A mutant) was expressed under control of a cytomegalovirus promoter. GFP was expressed via the same transcript following an IRES sequence, both downstream of dnCREB. The control vector expressed IRES-GFP alone.

NAc slice preparations. Similar to that described before (Dong et al., 2006), the rat was decapitated following isoflurane anesthesia. The brain was removed and glued to a block and sliced with a vibratome in $4^{\circ} \mathrm{C}$ artificial CSF (aCSF). Coronal slices of 300-450 $\mu \mathrm{m}$ thickness were then cut such that the preparation contained the signature anatomical landmarks (e.g., the anterior commissure) that clearly delineated the NAc subregions. After allowing $1-2 \mathrm{~h}$ for recovery, one slice was transferred from a holding chamber to a submerged recording chamber where it was continuously perfused with oxygenated aCSF maintained at $33^{\circ} \mathrm{C}$. It is important to note that temperature plays a key role in measuring the decay kinetics of NMDAR EPSCs. It has been shown that when the recording temperature is increased from 25 to $33^{\circ} \mathrm{C}$, the same recorded neurons exhibited NMDAR EPSCs with much larger amplitude $(\sim 1.6$ folds) and much faster decay time course ( $\sim 2.5$-folds) (Losi et al., 2002). Thus, the properties of NMDAR EPSCs measured at lower temperatures might be much different from that measured at $33^{\circ} \mathrm{C}$.

Electrophysiology. Standard whole-cell voltage-clamp recordings from NAc shell were done with a MultiClamp 700B amplifier (Molecular Device) in all electrophysiological experiments. The intracellular and extracellular solutions used can be found in our previous studies (Dong et al., 2006; Huang et al., 2007). The extracellular solution routinely contained picrotoxin $(0.1 \mathrm{mM})$ to block $\mathrm{GABA}_{\mathrm{A}} \mathrm{R}$ - mediated currents, and NBQX (5 $\mu \mathrm{M})$ for isolating NMDAR-mediated currents. When measuring regular EPSCs, presynaptic stimuli (intensity, 200-500 $\mu \mathrm{A}$; duration, 300-600 $\mu \mathrm{s}$; frequency, $0.1 \mathrm{~Hz}$ ) were applied through a bipolar microelectrode. The stimulating electrode was placed close to recorded neurons $(\sim 3-4$ cells away) and the amplitude of EPSCs was adjusted within $\sim 80-150$ $\mathrm{pA}$; both of these efforts were made to minimize the potential spatial effect (Williams and Mitchell, 2008). Amplitudes of AMPAR EPSC were calculated by averaging 25 EPSCs at $-80 \mathrm{mV}$ and measuring the peak (2 $\mathrm{ms}$ window) compared with the baseline ( $2 \mathrm{~ms}$ window). NMDAR EPSC amplitudes were calculated by averaging 25 EPSCs at $+40 \mathrm{mV}$ and mea- 
suring the amplitude ( $2 \mathrm{~ms}$ window) $35 \mathrm{~ms}$ after the EPSC peak compared with the baseline.

The coefficient of variation (CV) analysis was done as previously described (Kullmann et al., 1996; Huang et al., 2009). Briefly, CVs were estimated for epochs of 50 consecutive trials. Sample variances (SVs) were calculated for EPSC amplitudes and for noise sweeps. The CV was calculated as the square root of the difference for the sample variances [SV(EPSC) - SV(Noise)], divided by the mean. The CV of NMDAR EPSCs was higher than previously reported, because the NMDAR EPSC amplitude measurements were made $60 \mathrm{~ms}$ after EPSC onset in the absence of NBQX, not at the peak of the NMDAR EPSC, thus adding variance to the measurement. Minimal stimulation experiments were performed as described previously (Kullmann, 1994; Marie et al., 2005). Briefly, the frequency of presynaptic stimulation was set at $0.33 \mathrm{~Hz}$. After obtaining a small $(>40 \mathrm{pA})$ EPSCs at $-80 \mathrm{mV}$, stimulation intensity was reduced in small increments to the point that failures versus successes could be clearly distinguished visually. Stimulation intensity and frequency were then kept constant for the rest of the experiment. The amplitude of both AMPAR and NMDAR EPSCs resulting from single vesicle release is relatively large (e.g., $\sim 15 \mathrm{pA}$ for AMPAR mEPSCs) (Huang et al., 2007), which greatly facilitates the judgment of success versus failure. Failures versus successes were defined visually. The percentages of silent synapses were calculated using the equation: $1-\operatorname{Ln}\left(F_{-80}\right) / \operatorname{Ln}\left(F_{+40}\right)$, in which $F_{-80}$ was the failure rate at $-80 \mathrm{mV}$ and $F_{+40}$ was the failure rate $+40 \mathrm{mV}$.

Decay kinetics of NMDAR EPSCs were assessed using the time decaying from the peak amplitude to one-half peak amplitude of EPSC (Barria and Malinow, 2005). The NMDAR EPSCs used for analysis was obtained by averaging 20-30 consecutive individual EPSCs. Alternative measurements were also applied and similar results were obtained.

D-APV (D-aminophosphonovaleric acid), referred to as APV in this manuscript, was used to inhibit total NMDARs. Ro256981, at a concentration of $20 \mathrm{nM}$, was used to selectively inhibit NR2B-containing NMDARs. NBQX, APV, and Ro256981 were purchased from Tocris Bioscience and other chemicals were purchased from Sigma-Aldrich unless otherwise specified.

Western blot analysis of NMDAR subunits from NAc shell slices. We adapted a method from our previous study to quantify protein levels in virally manipulated NAc slices (Huang et al., 2007). Briefly, we isolated the NAc shell from $32 \mathrm{~d}$ old rats and put the tissues on slice culture films (Millipore) on the neural basal-A culture medium (containing B27 supplements; Invitrogen). One hour later, we dropped the virus solution (containing caCREB-GFP-, dnCREB-GFP-, or GFP-expressing sindbis viruses) on the tissues and continued to culture for $18 \mathrm{~h}$. We then collected and coded (to set up a blind analysis) the tissues for Western assay. Slices were homogenized and sonicated in lysis buffer containing proteinase and phosphatase inhibitors $(20 \mathrm{~mm}$ Tris, $50 \mathrm{~mm}$ Nacl, $1 \%$ Triton $\mathrm{X}-100,0.1 \%$ SDS, 1 mm EDTA, 1 mm EGTA, pH 7.4) followed by endover-end mixing for $30 \mathrm{~min}$ at $4^{\circ} \mathrm{C}$. The homogenates were centrifuged at $14,000 \mathrm{rpm}$ for $15 \mathrm{~min}$ at $4^{\circ} \mathrm{C}$. The supernatants were processed by SDSPAGE and subjected to Western blotting. Antibodies included NR2B monoclonal antibodies (Millipore) and $\beta$-actin monoclonal antibody (Sigma). Bands were visualized by enhanced chemiluminesence (GE Healthcare) and band intensities were quantified by NIH Image software. The total NMDAR subunit levels were normalized to the actin level in each sample.

Chromatin immunoprecipitation assay. Chromatin immunoprecipitation (ChIP) was performed following previously described methods (Kumar et al., 2005). Briefly, animals were treated with cocaine ( $15 \mathrm{mg} / \mathrm{kg}$ ) or saline for $5 \mathrm{~d}$. Bilateral 14 gauge NAc punches were pooled from five animals (10 punches); $n$ corresponds to each pool of animals. Punches were briefly fixed in 1\% formaldehyde; fixation was stopped using $2 \mathrm{M}$ glycine. One day before sample sonication, sheep anti-rabbit IgG magnetic beads were prepared by incubating appropriate magnetic beads with anti-phospho-CREB (rabbit polyclonal ChIP grade; Abcam) antibody overnight at $4^{\circ} \mathrm{C}$ under constant rotation in block solution. For each ChIP sample, five animals ( 10 punches) were pooled and sonicated on ice with a sonic dismembrator (Model F550; Fisher Scientific) once for $25 \mathrm{~s}$, followed by three $15 \mathrm{~s}$ sonications. Samples were centrifuged and supernatant was removed to a new tube. Each sample was immunoprecipitated with anti-rabbit antibodies directed against phospho-CREB. Eighty microliters of chromatin were removed from each sample to use as input (i.e., non-immunoprecipitated control). Reverse cross-linking was performed with $5 \mathrm{M} \mathrm{NaCl}, 0.5 \mathrm{M}$ EDTA, and Tris- $\mathrm{HCl}, \mathrm{pH} 6.5$, at $65^{\circ} \mathrm{C}$, and proteins were digested with RNA-grade proteinase K (Invitrogen). DNA was purified and resuspended in $200 \mu \mathrm{l}$ of RNase-DNase-free water (Invitrogen).

Real-time PCR. For ChIP samples, primers were designed to amplify products of $150 \mathrm{bp}$ in the regions immediately $5^{\prime}$ to the start site of NR2A and NR2B. PCR was performed using an Applied Biosystems 7500 quantitative reverse transcription-PCR system with the following cycle parameters: $2 \mathrm{~min}$ at $95^{\circ} \mathrm{C} ; 40$ cycles of $95^{\circ} \mathrm{C}$ for $1 \mathrm{~min}, 60^{\circ} \mathrm{C}$ for $33 \mathrm{~s}, 72^{\circ} \mathrm{C}$ for $33 \mathrm{~s}$; and graded heating to $95^{\circ} \mathrm{C}$ to generate dissociation curves for confirmation of single PCR products. Data were analyzed by comparing $\mathrm{C}(\mathrm{t})$ values of the treatment condition (cocaine) to the control condition (saline) using the $2^{-\Delta \Delta C(t)}$ method (Kumar et al., 2005) (Livak and Schmittgen, 2001). Briefly, the input $C(t)$ values for each sample were subtracted from the immunoprecipitated $\mathrm{C}(\mathrm{t})$ values $(\Delta \mathrm{C}(\mathrm{t}))$. These values were averaged for all of the saline samples and this value (average $\Delta \mathrm{C}(\mathrm{t}))$ was subtracted from the $\Delta \mathrm{C}(\mathrm{t})$ generated for each sample. This gives the $\Delta \Delta \mathrm{C}(\mathrm{t})$ value for each sample. Two was raised to the negative power of each $\Delta \Delta \mathrm{C}(\mathrm{t})$, giving the fold change induced by cocaine for NR2A and NR2B.

Imaging dendritic spines. Dendritic spines of NAc MSNs were labeled and imaged as described previously (Shen et al., 2008). Briefly, all rats were perfused transcardially $(20 \mathrm{ml} / \mathrm{min})$ with $0.1 \mathrm{M}$ sodium phosphate buffer (PB), followed by $200 \mathrm{ml}$ of $1.5 \%$ paraformaldehyde (PFA) in 0.1 $\mathrm{M} P B$. As has been previously reported, the use of $1.5 \%$ rather than the more traditional 4\% PFA was critical in obtaining maximal dye filling of small diameter spines. Brains were removed and postfixed in the same fixative for $1 \mathrm{~h}$ at room temperature before coronal slices of $150 \mu \mathrm{m}$ thickness were prepared using a vibratome at room temperature. The slices were collected in PB-saline and mounted before DiI labeling. DiI fine crystals (Invitrogen) were delivered under a dissecting microscope onto the surface of slices using a borosilicate glass micropipette with a sharp and elongated tip, controlled by a micromanipulator (Sutter). Dil was allowed to diffuse in PBS for $24 \mathrm{~h}$ at $4^{\circ} \mathrm{C}$, and then labeled sections were fixed in 4\% PFA at room temperature for $1 \mathrm{~h}$. After brief wash in PBS, tissues were mounted in aqueous medium prolong (Invitrogen).

An Olympus confocal microscope was used to image the labeled sections. DiI was excited using the Helium/Neon $543 \mathrm{~nm}$ laser line. The entire profile of each DiI-positive neuron to be quantified was acquired using a $40 \times$ oil-immersion objective. After the neuron was scanned and confirmed as the NAc shell MSN, its dendrites were focused using a 100X oil-immersion objective and scanned at $1 \mu \mathrm{m}$ intervals along the $z$-axis for a maximum of 200 planes; the final image of each dendrite was obtained by stacking all planes. Analyses were performed on two-dimensional projection images using the software Image $(\mathrm{NIH})$. Based on previous results (Robinson and Kolb, 2004), secondary and tertiary dendrites were preferentially sampled. For each neuron, one or two dendrites of $>20 \mu \mathrm{m}$ in length were analyzed. For each of the eight rats, at least 10 neurons were analyzed. We divided the spines into two large categories. The filopodialike protrusion was operationally defined as the protrusion without a clear head or with a head with a diameter $<2$ times the diameter of its neck. The mushroom-like protrusion was operationally defined as the headed protrusion with the diameter of the head $>2$ times of its neck.

For experiments involving dnCREB, dendritic spines were imaged by GFP expression by confocal microscopy and quantified by observers blind to the experimental conditions. This method has been validated in several previous publications (Russo et al., 2009; Maze et al., 2010).

Behavioral tests. Rats were anesthetized with zyket $(87 \mathrm{mg} / \mathrm{kg}$ of ketamine plus $13 \mathrm{mg} / \mathrm{kg}$ xylazine) and placed into a stereotaxic apparatus. Bilateral 26 gauge stainless steel guide cannulae (Plastics One) were implanted into the NAc shell (1.0 from bregma, $\pm 1.0 \mathrm{~mm}$ from midline, and $-6.0 \mathrm{~mm}$ from skull) and mini osmotic pumps were implanted. Rats recovered 1 week before experimentation. The perfusion rate of the osmotic pump was set at $0.1 \mu \mathrm{l} / \mathrm{h}$. The in vivo perfusion concentrations of Ro256981 and APV were set at 20 and $500 \mathrm{~nm}$, respectively. Rats that 
received intra-NAc saline perfusion through mini pumps were used as sham controls. Rats were allowed to habituate to the locomotor chamber $(16$ " $\mathrm{L} \times 16$ " $\mathrm{W} \times 12$ " $\mathrm{H}) 1 \mathrm{~h}$ per day for $2 \mathrm{~d}$ before the day 0 injection of saline. Rats then received a $15 \mathrm{mg} / \mathrm{kg}$ daily intraperitoneal cocaine injection for $5 \mathrm{~d}$ (the same volume of saline injection was used as control). Locomotor activity was immediately measured for $1 \mathrm{~h}$ and the data from the first 15 min were presented. In a subset of rats, the spontaneous locomotor activity was measured in the same setup before cocaine treatment. After $2 \mathrm{~d}$ of withdrawal from the last cocaine/saline injection, rats received a challenge injection of cocaine $(12 \mathrm{mg} / \mathrm{kg})$ and their locomotor activity was tested immediately. At the end of the experiment, all cannulae placements were verified with neutral red staining of coronal brain sections.

Data acquisition, analysis, and statistics. In experiments of CV assays, minimal stimulation assays, and Western blot assays, all data were obtained blindly. In experiments involving measuring the decay kinetics of NMDAR EPSCs and mNR1-containing NMDARs, $\sim 75 \%$ of the data were obtained blindly. All results are shown as mean \pm SEM; $n$ refers to the number of animals examined. For electrophysiological experiments, two to three cells were recorded from each rat. The total number of cells examined in each set of experiments was also presented (referred to as $m$ ). For morphological experiments, five to 20 dendrites were examined. The total number of dendrites in each set of experiments was also presented (referred to as $m$ ). All statistics were performed based on animals. In electrophysiological and morphological experiments, the averaged value of the measured parameters from all examined cells or dendrites was used to represent the value of each rat for statistics. Statistical significance was assessed using $t$ tests, or one-way or two-way ANOVA with Bonferroni posttests.

\section{Results}

\section{Cocaine-induced generation of silent synapses is initiated by} activation of CREB

To identify the molecular mechanism underlying cocaine-induced generation of silent synapses, we focused on CREB, a transcription factor activated in response to cocaine exposure (for review, see Carlezon et al., 2005) and implicated in synaptogenesis (for review, see Lonze and Ginty, 2002). To test a requirement for CREB in generation of silent synapses, we expressed caCREB or dnCREB by means of the sindbis viral expression system by stereotaxic injection directly into the NAc in vivo.

We examined cocaine-generated silent synapses using two independent functional electrophysiological assays, CV and minimal stimulation assay (Huang et al., 2009). The CV is dependent on the number of recruited synapses during trials of evoked EPSCs (Kullmann, 1994). Comparing the CV of the AMPAR component (measured at $-80 \mathrm{mV}$ ) and the $\mathrm{CV}$ of the NMDAR (measured at $+40 \mathrm{mV}$ ) elicited by the same stimulation strength provides a relative measure of changes in the receptor content of synapses. We compared the variability of evoked NMDAR EPSCs to that of AMPAR EPSCs as the ratio CV(NMDAR)/CV (AMPAR) in different experimental groups. Expression of caCREB for $24 \mathrm{~h}$ decreased the CV of NMDAR EPSCs $\left[F_{(5,33)}=\right.$ $4.65, p<0.01$, one-way ANOVA; $p<0.05$, caCREB vs uninfsaline or GFP-saline; Bonferroni posttest; $\mathrm{n} / \mathrm{m}$ (total animals/ total cells) $=6 / 10$ for caCREB, 12/29 for uninf-saline, and 5/9 for GFP-saline] and CV(NMDAR)/CV(AMPAR) $\left(F_{(5,33)}=13.57\right.$, $p<0.01$, one-way ANOVA; $p<0.01$, caCREB vs uninf-saline or GFP-saline, Bonferroni posttest) (Fig. $1 A, B)$ with no significant effect on the CV of AMPAR EPSCs $\left(F_{(5,33)}=1.81, p=0.14\right.$, one-way ANOVA), consistent with an increase in silent synapses. A similar reduction in the CV of NMDAR EPSCs $(p<0.01$, uninf-saline vs uninf-cocaine, Bonferroni posttest; $n / m=12 / 29$ for uninf-saline and 5/9 for uninf-cocaine) and CV(NMDAR)/ CV(AMPAR) ( $p<0.01$, uninf-saline vs uninf-cocaine, Bonfer- roni posttest) was observed when rats were treated for $2.5 \mathrm{~d}$ with cocaine, a regimen adapted for the time course of the viral manipulations. Importantly, the changes in $\mathrm{CV}$ elicited by this shortened cocaine procedure were comparable to those of our previous study with a $5 \mathrm{~d}$ procedure (Huang et al., 2009).

Whereas expression of dnCREB alone did not affect the $\mathrm{CV}$ of NMDAR EPSCs ( $p=1.0$, dnCREB-saline vs GFP-saline or uninf-saline, Bonferroni posttest; $n / m=5 / 9$ for dnCREB-saline, 5/9 for GFP-saline, and 12/29 for uninf-saline) and the ratio of CV(NMDAR):CV(AMPAR) ( $p=1.0$, dnCREB vs GFP-saline or uninf-saline, Bonferroni posttest) (Fig. $1 A, B$ ) in saline-treated rats, it prevented the effects of cocaine on the $\mathrm{CV}$ (NMDAR)/ $\mathrm{CV}$ (AMPAR) in the $2.5 \mathrm{~d}$ procedure $(p=0.49$, dnCREB-cocaine vs uninf-saline, $p<0.05$, dnCREB-cocaine vs uninfcocaine, Bonferroni posttest; $n / m=6 / 9$ for dnCREB-cocaine) (Fig. 1A,B). Note that expression of GFP alone did not affect either of the above parameters [ $p=1.0$, GFP vs uninf-saline for CV-AMPAR, CV-NMDA, and CV(NMDAR)/CV(AMPAR), Bonferroni posttests] (Fig. 1A,B). The findings that neither GFP nor dnCREB did not by itself alter the NMDA or AMPA CV, demonstrate that delivery of viral vectors under our experimental conditions did not themselves affect these parameters. As such, the manipulated groups (virally infected cells) were directly compared with uninfected cells in most comparisons.

In the minimal stimulation assay (see Material and Methods, above), we adjusted the stimulation strength of the AMPAR EPSCs such that successful trials with a measurable EPSC were interleaved with trials with no detectable EPSC (failures) (Fig. $1 C)$. We calculated the estimated percentage of AMPAR-silent synapses from the failure rates of AMPAR EPSCs and NMDAR EPSCs (for details, see Material and Methods, above) (Kullmann, 1994; Marie et al., 2005; Huang et al., 2009). Expression of caCREB for $24 \mathrm{~h}$ induced an increase in the percentage of failures, a predictor of the percentage of silent synapses in cells of salinetreated animals, compared with GFP-expressing control cells $\left(F_{(6,32)}=12.06, p<0.01\right.$, one-way ANOVA; $p<0.01$, caCREB vs uninf-saline or GFP-saline Bonferroni posttest; $n / m=6 / 12$ for caCREB-saline, 5/8 for uninf-saline, and 5/10 for GFP-saline) (Fig. $1 C, D$ ). Similarly, cocaine administration in the $2.5 \mathrm{~d}$ procedure increased the percentage of failures, consistent with the generation of silent synapses in control and GFP-expressing neurons, confirming our previous results with a $5 \mathrm{~d}$ procedure $(p<0.05$, uninf-saline vs uninf-cocaine; $p<0.05$, GFP-saline vs GFPcocaine, Bonferroni posttest; $n / m=5 / 8$ for uninf-cocaine and $5 / 10$ for GFP-cocaine) (Fig. 1C,D) (Huang et al., 2009). Whereas dnCREB expression did not significantly alter the percentage of silent synapses in saline-treated rats $(p=1.0$, dnCREB-saline vs uninf-saline or GFP-saline; Bonferroni posttest; $n / m=5 / 12$ ), expression of dnCREB prevented the generation of silent synapses in cocaine-treated rats ( $p<0.05$, dnCREB-cocaine vs uninf-cocaine; $p<0.01$, dnCREB-cocaine vs GFP-cocaine; $p=$ 1.0, dnCREB-cocaine vs uninf-saline or GFP-saline, Bonferroni posttest; $n / m=8 / 16$ for dnCREB-cocaine) (Fig. $1 C, D$ ).

In the above experiments, we used relatively young $(\sim 30 \mathrm{~d}$ old) rats. Young rats exhibit higher basal level of silent synapses (Durand et al., 1996; Hsia et al., 1998; Kerchner and Nicoll, 2008), which may lead to different behavioral responses to drugs of abuse compared with more matured rats (Andersen et al., 2002; Tirelli et al., 2003). However, it has been shown that silent synapses are generated in the NAc of both young and adult rats upon cocaine exposure (Huang et al., 2009), and similar to adult rats $(\sim 65 \mathrm{~d})$, young rats used in this study exhibited robust cocaineinduced locomotor sensitization. These findings suggest that ac- 
A

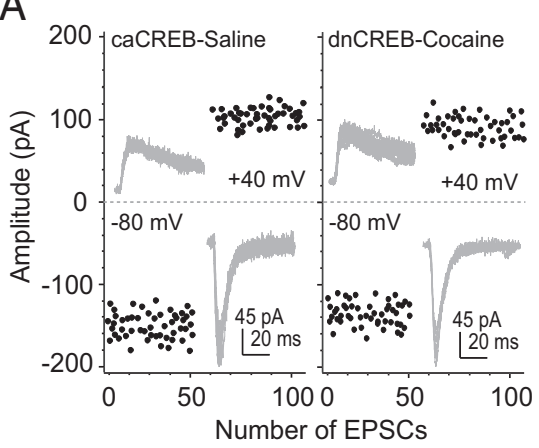

C

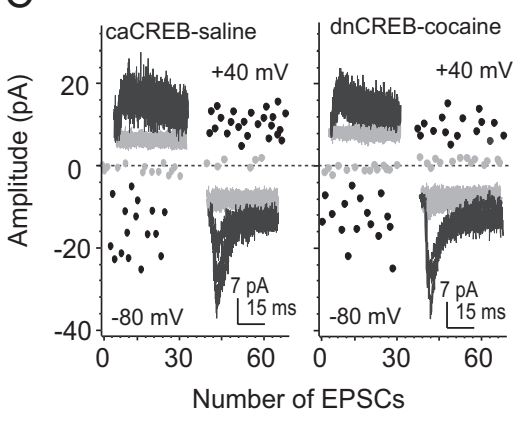

$\mathrm{B}$

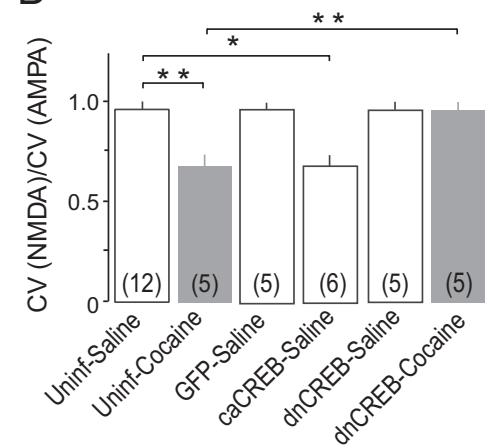

D

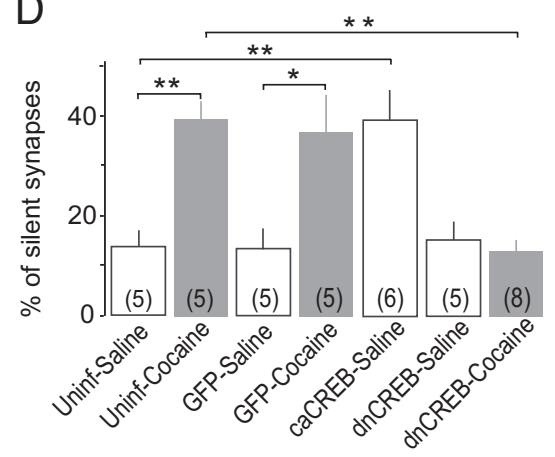

Figure 1. Activation of CREB-mediated cocaine-induced generation of silent synapses in NAC MSNs. CV analysis of AMPAR and NMDAR EPSCs in control, caCREB- $(24 \mathrm{~h}$ ), or dnCREB- $(72 \mathrm{~h}$ ) expressing MSNs from saline- or cocaine- ( $2.5 \mathrm{~d}$ procedure; analysis $16 \mathrm{~h}$ after last injection; see Material and Methods) treated rats. $A$, Example traces and amplitude plots were from a caCREB-saline and a dnCREB- cocaine MSN, showing the variability of multiple sweeps at each holding potential. $B$, A summary shows that repeated exposure to cocaine decreased the ratio of CV-NMDAR:CV-AMPAR in NAC MSNs, expression of GFP alone did not affect this ratio, expression of caCREB alone decreased this ratio, expression of $d n C R E B$ in saline-treated rats did not cause changes in this ratio, and expression of $d n C R E B$ prevented the cocaine-induced decrease in this ratio. C, Minimal stimulation assays in control, caCREB- or $\mathrm{dnCREB}$-expressing MSNs from saline- or cocaine-treated rats. Example traces and amplitude plots were from a caCREB-saline and a dnCREB - cocaine MSN, showing multiple sweeps at each holding potential, where failures are marked in gray and successes in black. $D$, A summary shows that repeated exposure to cocaine increased the estimated percentage of silent synapses in NAc MSNs, expression of GFP alone did not affect this percentage, expression of caCREB was sufficient to increase this percentage in salinetreated rats, expression of dnCREB in saline-treated rats did not cause changes in this percentage, and expression of $d n C R E B$ prevented cocaine-induced increase in this percentage. Numbers in parentheses indicate number of cells; ${ }^{*} p<0.05 ;{ }^{* *} p<0.01$.

tivation of CREB in NAc neurons is both necessary and sufficient for cocaine-induced generation of silent synapses.

\section{Exposure to cocaine generates silent synapses across different neuronal subtypes in the NAc}

Neurons in the NAc are highly heterogeneous and can be divided into different subpopulations depending on different criteria. For example, based on receptor/transmitter subtypes, the NAc neurons can be divided into two subpopulations, one ( $\sim 50 \%$ of total NAc neurons) coexpressing dopamine D1-class receptors and substance $\mathrm{P}$, and the other ( $\sim 50 \%$ of total NAc neurons) coexpressing dopamine D2-class receptors and enkephalin (Le Moine and Bloch, 1995; Gong et al., 2003; Lee et al., 2006). This distribution includes a heterogeneous population of 5-10\% interneurons. Based on electrophysiological properties, NAc neurons can be categorized as neurons with $(\sim 24 \%)$ or without gap junctions with their neighboring NAc neurons (O'Donnell and Grace, 1993). Based on behavioral correlates, it has been shown that $\sim 10 \%$ (43 of 420 cells) of NAc neurons respond to a rewarding stimulus (Apicella et al., 1992; Schultz et al., 1992). Thus, a key question is whether cocaine-induced generation of silent synapses occurs in all NAc neurons, or just in a subtype of NAc neurons. To detect potential differences in cocaine responses among these various neuronal subpopulations (e.g., responders vs nonresponders), we characterized the distribution of the electrophysiological parameters, including percentage of silent synapses (for calculation, see Materials and Methods, above) and decay time constant of NMDARmediated EPSC across the recorded NAc neurons. As shown in Figure $2 A$, the NAc neurons from saline-treated rats $(n=53)$ exhibited a monomodal pseudonormal distribution with a median at $\sim 0.1$ (i.e., percentage of silent synapses is $\sim 10 \%$ ). NAc neurons from cocaine-treated rats $(n=47)$ also exhibited a monomodal distribution with a median at $\sim 0.4$ (percentage of silent synapses is $\sim 40 \%$ ) (Fig. $2 B$ ). These results suggest that exposure to cocaine changed the median (of the portion of silent synapses) but not the distribution (e.g., no sign of bimodal distribution was observed).

To further focus on a hypothetical situation in which $\sim 50 \%$ of NAc neurons were the responders and $\sim 50 \%$ were not, we built a hypothetical distribution model in which we operationally defined the distribution of responders as that in Figure $2 B$ and the distribution of nonresponders as that in Figure $2 \mathrm{~A}$. We pooled the same number of cells $(\sim 45)$ from each group, and the pooled distribution exhibited a typical bimodal property. This bimodal distribution (Fig. $2 C$, solid curve) can be computationally peeled into two monomodal distributions (Fig. 2C, dashed curves) corresponding to the distribution curves.

Thus, results from the above analyses suggest that it is likely that, following cocaine exposure, silent/nascent synapses are generated across different neuronal subtypes in NAc neurons.

\section{Cocaine-induced NR2B expression is mediated through CREB activation}

Cocaine-induced generation of silent synapses appears to arise from insertion of NR2B subunit-enriched NMDARs (Huang et al., 2009). We examined whether this increase is mediated by CREB activation. We first treated rats with a $5 \mathrm{~d}$ cocaine procedure and immunoprecipitated chromatin-bound activated CREB [phopho-CREB (pCREB)] from NAc extracts. The levels of coprecipitated NR2A and NR2B promoter fragments were quantified by PCR and levels in cocaine-treated animals were normalized to levels in saline-treated control rats (Fig. $3 A$ ). Whereas the pCREB bound levels of NR2A promoter fragments did not change upon cocaine exposure, the pCREB bound levels of NR2B increased more than twofold, suggesting a specific activation of the NR2B gene by CREB (saline NR2A, $1.00 \pm 0.16, n=$ 7 vs cocaine NR2A, $1.25 \pm 0.30, n=6, p>0.05$; saline NR2B, $1.00 \pm 0.16, n=5$ vs cocaine NR2B, $3.46 \pm 0.70, n=6, p<0.05$ ).

We next tested whether CREB activation is sufficient for increasing NR2B protein levels. We incubated NAc tissue with sindbis viruses expressing caCREB or $\mathrm{dnCREB}$ and examined the 
protein level of NR2B subunits $24 \mathrm{~h}$ later. When normalized to the loading control actin, our results show that expression of caCREB increased total cellular NR2B protein abundance in the NAc more than threefold, whereas expression of dnCREB or GFP had little or no effect (relative level to uninfected tissues at total level: GFP $0.89 \pm$ 020, $n=4$; caCREB, $3.58 \pm 0.56, n=5$; dnCREB, $1.10 \pm 0.18, n=5 ; F_{(3,16)}=$ $11.6, p<0.01$, one-way ANOVA; $p<0.01$ caCREB vs uninf, GFP, or dnCREB, Bonferroni posttest) (Fig. 3B,C). Although the use of caCREB does not mimic the endogenous time course of CREB activation, the results show that CREB activation by itself is sufficient to induce upregulation of NR2B.

A selective upregulation of NR2B-containing NMDARs, as demonstrated here and in our previous study (Huang et al., 2009), would increase the relative portion of NR2B-containing NMDARs across all synaptic NMDARs. This scenario predicts that the overall (evoked) NMDAR EPSCs should be shaped by NR2B subunits. To test this prediction, we combined cocaine treatment with CREB manipulations and measured the time course of the decay of the NMDARmediated EPSC, a sensitive biophysical measurement of the relative contribution of synaptic NR2B-containing NMDARs, but may also reflect a small $(<15 \%)$ contribution of NR2D-containing NMDARs, known to be expressed in mouse striatum (Logan et al., 2007). Exposure to cocaine (the 2.5 cocaine procedure) induced a marked increase in the decay kinetics of NMDAR EPSCs (assessed by the time decayed from the peak to one-half peak amplitude, or $\left.T_{1 / 2}\right)$ in NAc neurons $\left(F_{(5,35)}=9.25, p<0.01\right.$, one-way ANOVA; $p<0.05$, uninf-saline vs uninf-cocaine; Bonferroni posttest; $n / m=$ 15/29 for uninf-saline and 5/9 for uninf-cocaine) (Fig. $3 D, E$ ). Furthermore, this effect of cocaine was mimicked by expression of caCREB ( $p<0.01$, caCREB-saline vs uninf-saline or GFP-saline, Bonferroni posttest; $n / m=6 / 11$ for caCREB-saline and $5 / 10$ for GFP-saline) (Fig. 3D,E), and was prevented by expression of dnCREB ( $p<0.05$, dnCREB-cocaine vs uninf-cocaine, $p=1.0$, dnCREB-cocaine vs uninf-saline or GFP-saline, Bonferroni posttest; $n / m=5 / 16$ for dnCREB-cocaine) (Fig. $3 D, E$ ).

Together, our results suggest that activation of CREB is required for the cocaine-induced increase in synaptic incorporation of NR2B-containing NMDARs and that activation of CREB alone is sufficient to trigger NR2B-containing receptors in NAc MSNs following exposure to cocaine.

\section{Cocaine-induced increase in spine number is mediated through CREB}

Chronic exposure to cocaine increases the number of spines in NAc neurons, which persists for weeks after drug discontinuation (Kolb et al., 2003; Robinson and Kolb, 2004). We examined the number of dendritic spines in NAc neurons following the $5 \mathrm{~d}$ cocaine procedure used in our previous electrophysiology experiments (Huang et al., 2009). To quantify the spine density, we labeled neurons in lightly fixed tissues with the lipophilic fluorescent dye DiI and examined dendritic spines using confocal microscopy. Two days after the $5 \mathrm{~d}$ cocaine protocol, the numbers of filopodia-like $\left(t_{(6)}=-2.74, p<0.05, t\right.$ test; $n / m=4 / 74$ for saline and 4/55 for cocaine) and mushroom-like $\left(t_{(6)}=-2.89, p<\right.$
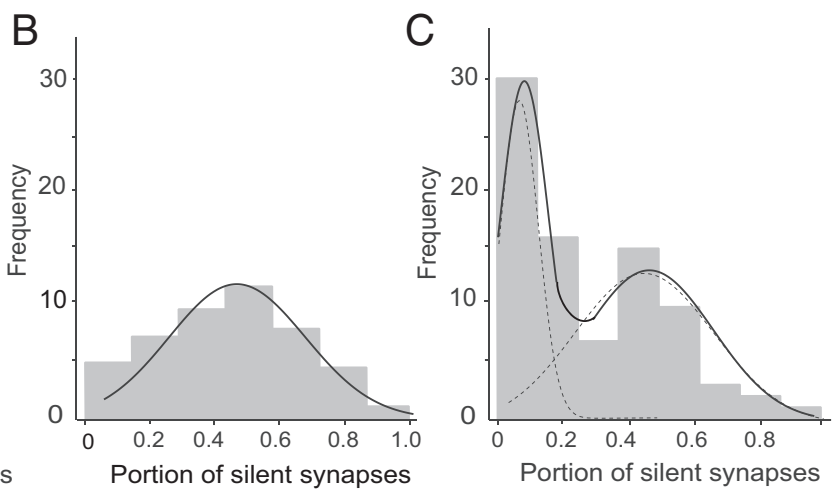

Figure 2. Monomodal distribution of portion of silent synapses and decay kinetics of NMDAR responses in control and cocainesynapses in NAC MSNs from saline-treated rats was consistent with a single-peak normal modal distribution. $\boldsymbol{B}$, The distriof nonresponders. This hypothetical distribution was constructed based on the data in $\boldsymbol{A}$ and $\boldsymbol{B}$, which was operationally used to represent responders and nonresponders, respectively. The distribution was best fit by bimodal distributions (dashed lines for two monomodal distributions that make up the overall bimodal distribution).
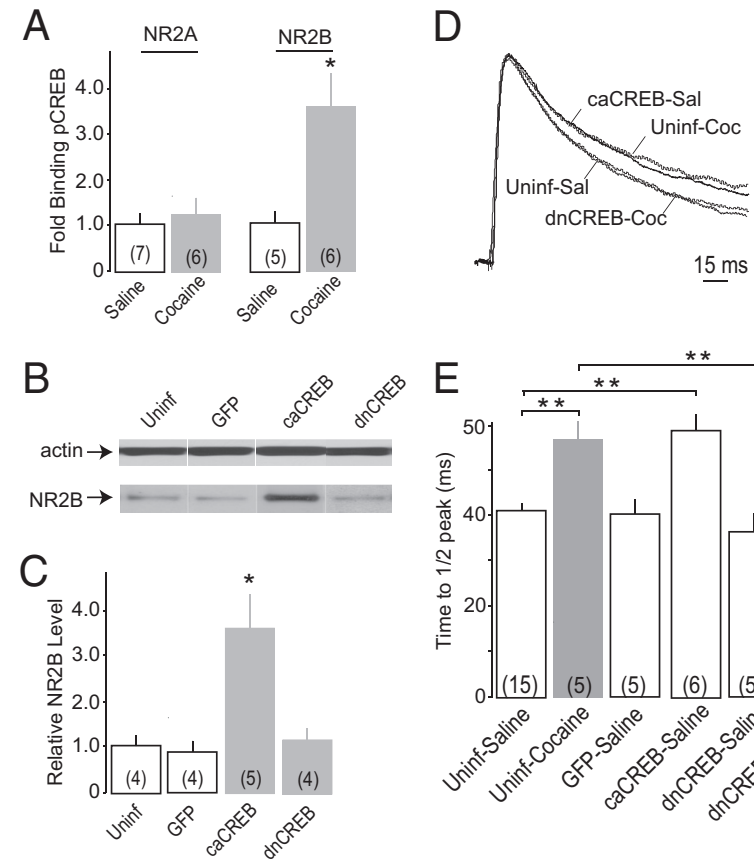

Figure 3. Cocaine induces CREB-mediated increases in NR2B expression. $A$, ChIP analysis with real-time $P C R$ of phospho-CREB binding to NR2A and NR2B gene promoters in saline- and cocaine- (5 d procedure) treated NAc samples. $\boldsymbol{B}, \boldsymbol{C}$, Sample $(\boldsymbol{B})$ and quantification $(\boldsymbol{C})$ of Western blots of NAc extracts for NR2B levels after viral-mediated gene expression of $d n C R E B$ and caCREB. D, Scaled example EPSCs recorded at $+40 \mathrm{mV}$ from uninf-saline (Sal), caCREB-saline, uninf-cocaine ( $C o c)$, and dnCREB-cocaine. $E$, A summary shows that repeated exposure to cocaine significantly prolonged the decay kinetics of NMDAR EPSCs in NAC MSNs, expression of GFP alone did not affect the decay kinetics, expression of caCREB alone mimicked the effect of cocaine on the decay kinetics of NMDAREPSC in NAc MSNs, expression of dnCREB alone did not affect the decay kinetics of NDMAR EPSCS, and expression of dnCREB prevented the effect of cocaine on the decay kinetics of NMDAR EPSCs in NAC MSNs. Numbers in parentheses indicate number of cells; ${ }^{*} p<0.05 ;{ }^{* *} p<0.01$.

$0.05, t$ test) protrusions, as well as the total (filopodia + mushroom) protrusions $\left(t_{(6)}=-3.45, p<0.05, t\right.$ test $)$ on the distal dendrites of NAc MSNs were significantly increased (Fig. $4 A, B)$. Furthermore, when pooling examined dendrites from 

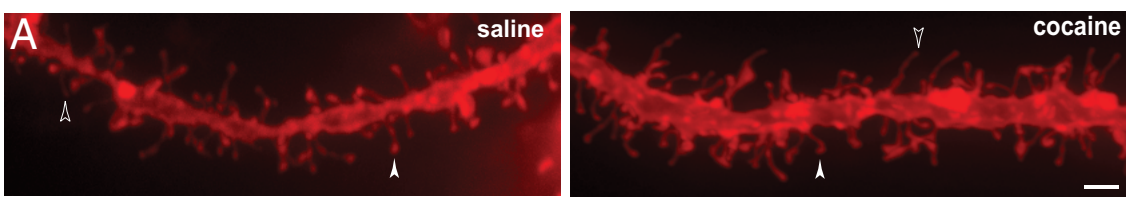

B
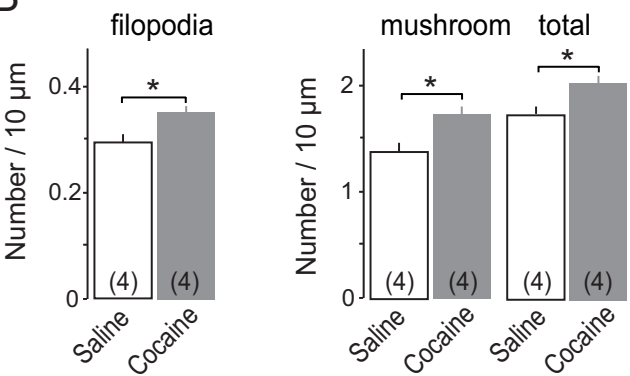

$\mathrm{C}$
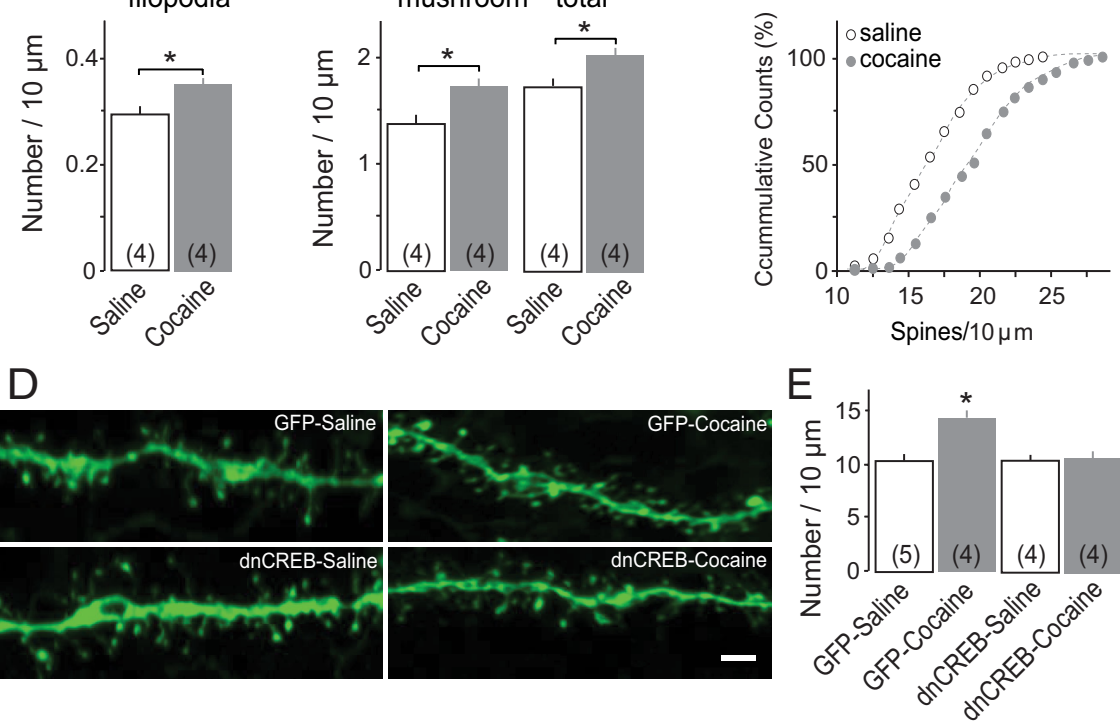

Figure 4. Generation of new spines in cocaine- ( $5 \mathrm{~d}$ procedure) treated rats can be prevented with $\mathrm{dnCREB}$ expression. $\boldsymbol{A}$, Example dendrites of NAc MSNs from saline- (left) and cocaine- (right) treated rats, imaged after Dil labeling with a confocal microscope and two-dimensional projection. $\boldsymbol{B}$, Summarized data showing that the numbers of filopodia, mushroom-like spines, and the total protrusions are all increased in dendrites of NAC MSNs from cocaine-treated rats. $C$, Cumulative plots showing that the cocaine-induced increase in spine density is evenly distributed across examined dendrites. $\boldsymbol{D}$, Example dendrites of GFP-infected MSNs from saline- (top left) or cocaine- (top right) treated rats and dnCREP-expressing MSNs from saline- (bottom left) or cocaine(bottom right) treated rats. $\boldsymbol{E}$, Summarized data showing the increased spine density of cocaine-treated, GFP-positive MSNs compared with saline-treated animals, and a blockade of the cocaine-induced increase in dnCREB-expressing neurons. Numbers in parentheses indicate number of cells. ${ }^{*} p<0.05$.

all animals together, the spine densities in the cumulative plot exhibited a monomodal distribution in saline-treated rats, and this monomodal distribution was not altered by cocaine treatment (Fig. 4C). This distribution pattern suggests that dendrites within the NAc were evenly affected following exposure to cocaine, supporting our electrophysiological data on the monomodal distribution of the effects on individual neurons (Fig. 2).

In agreement with the electrophysiological data, the increase in spine number after repeated cocaine administration was prevented by viral-mediated dnCREB expression compared with expression of GFP alone (drug factor, $F_{(1,13)}=19.70, p<0.01$; virus factor, $F_{(1,13)}=13.59, p<0.01$; drug $\times$ virus, $F_{(1,13)}=19.11, p<$ 0.01 , two-way ANOVA; $p<0.05$, GFP-cocaine vs GFP-saline, or dnCREB-saline, or dnCREB-cocaine; $p>0.05$, dnCREB-cocaine vs GFP-saline or dnCREB-saline, Tukey's multiple comparison posttest) (Fig. 4D,E). In these experiments, we counted spines visualized by the GFP fluorescence of the virally transduced neurons according to published protocols (Russo et al., 2009; Maze et al., 2010). Although this method reveals a smaller total number of spines compared with the DiI-stained neurons, the relative increase caused by repeated cocaine administration is consistent between the two methods. In conclusion, these results indicate a requirement of CREB activation for the cocaineinduced increase in spine number.
Potential role of silent synapses in cocaine-induced locomotor sensitization Finally, we explored the potential role of silent synapses in cocaine-induced locomotor sensitization. Silent synapses are generated gradually during early exposure (3-4 d) over the $5 \mathrm{~d}$ cocaine procedure (Huang et al., 2009), with a time course similar to that of the development of cocaine-induced locomotor sensitization (Wolf, 1998; Kalivas, 2007; Kauer and Malenka, 2007). Without highly selective approaches to manipulate silent synapses, we focused on NR2B-containing NMDARs within the NAc. Our experimental design was to bilaterally and chronically perfuse the NR2B-selective antagonist Ro256981 into the NAc shell (Fig. 5A) through preimplanted osmotic mini-pumps. As controls, rats with intra-NAc sham surgery and rats without surgery were tested with the $5 \mathrm{~d}$ cocaine procedure. Both control groups exhibited similar patterns of cocaineinduced locomotor sensitization upon repeated cocaine injections (control-cocaine $X$ sham-cocaine: $F_{(1,14)}=0.27, p=0.95$, two-way ANOVA) (Fig. 5B) and similar basal locomotor activity upon saline injection (control-saline $\times$ sham-saline: $F_{(1,12)}=$ $0.28, p=0.94$, two-way ANOVA with repeated measure over day) (Fig. 5B). This result indicates that the intra-NAc surgery did not affect basal and cocaine-induced locomotor responses. We next verified a concentration of Ro256981 that could effectively inhibit NR2B-containing NMDARs with minimal side effects. We examined the inhibitory effect of Ro256981 on NMDAR EPSCs at different concentrations and observed that at 20-200 nM, NMDAR EPSCs exhibited the first high affinity inhibition that was likely due to NR2B-selective inhibition (percent inhibition: $2 \mathrm{~nm}, 4.7 \pm 4.2, n=3 ; 20 \mathrm{~nm}, 33.9 \pm 5.5, n=10 ; 200$ nм, $35.4 \pm 6.1, n=6$ ) (Fig. 5C,D). One caveat of this pharmacological approach is that, if considered at the overall NMDAR level, application of $20 \mathrm{~nm}$ Ro256981 would cause a partial inhibition of total NMDARs by $\sim 35 \%$. This decrease in total NMDAR activity may produce some behavioral effect and thus complicate the interpretation of Ro256981-induced behavioral alteration. To address this potential caveat, we also verified that the nonselective NMDAR antagonist APV at the low concentration of $0.5 \mu \mathrm{M}$ inhibited total NMDAR EPSCs to a similar degree ( $39.4 \pm 6.2 \%, n=6$ ) as $20 \mathrm{~nm}$ Ro256981 (Fig. $5 D$ ). However, application of APV did not alter the decay kinetics of NMDAR EPSCs as found for Ro256981 (percent decrease in $T_{1 / 2}: 20 \mathrm{~nm}$ Ro256981, $11.2 \pm 1.5, n=10 ; 0.5 \mu \mathrm{M}$ $\mathrm{APV}, 3.3 \pm 2.5, n=6$ ) (Fig. $5 E$ ). Thus, using APV at $0.5 \mu \mathrm{M}$ in parallel with Ro256981 would allow us to clarify the potential behavioral alterations resulting from partial inhibition of total NMDARs.

We next examined the potential effects of intra-NAc perfusion of APV (500 nM) and Ro256981 (20 nM) on basal locomotor activity. Rats receiving intrsa-NAc perfusion of APV or Ro256981 exhibited similar basal activity as control rats or rats receiving 
sham surgery $(p>0.2$ between any two groups, two-way ANOVA with repeated measure over day) (Fig. $5 F$ ). To verify that Ro256981 via our intra-NAc perfusion setup could rapidly achieve maximal pharmacological and behavioral effects, we used the identical experimental procedure to perfuse the AMPAR-selective antagonist NBQX at a low concentration (1 $\mu \mathrm{M})$. It has been demonstrated that inhibiting the NAc AMPARs prevents druginduced locomotor response (Kaddis et al., 1993; Burns et al., 1994; Li et al., 1999; David et al., 2004). In the identical experimental setup that we used (see below), intra-NAc perfusion of a low concentration of NBQX blocked the cocaineinduced acute increases in locomotor activity (Fig. 5G). This result verifies that a brief preceding period $(\sim 15 \mathrm{~min})$ of intra-NAc perfusion is sufficient for loaded pharmacological agents to achieve effective concentrations.

After verifying the experimental approaches, we started the core experiments. Shortly after the intra-NAc perfusion started, rats received one injection of saline (on day 0 ), followed by a 5 day cocaine regimen starting from day 1 . A challenge injection of cocaine $(12 \mathrm{mg} / \mathrm{kg}$ ) was given on day 8 , following a $2 \mathrm{~d}$ withdrawal period (days 6-7). The intra-NAc perfusion of Ro256981 $(20 \mathrm{nM})$ or APV $(0.5 \mu \mathrm{M})$ was applied from day -1 until day 8 . Rats receiving only sham treatment developed steady cocaine-induced locomotor sensitization $(p<0.01$, day 5 vs day $1 ; p<0.01$, day 8 vs day 1 ) (Fig. $5 H)$. The development of cocaine-induced locomotor sensitization was not affected by intra-NAc perfusion of a low concentration of APV $(p<0.01$, day 5 vs day $1 ; p<0.01$, day 8 vs day 1) (Fig. $5 H$ ). However, the development of locomotor sensitization was prevented by intra-NAc perfusion of Ro256981; indeed, in Ro256981-perfused rats, cocaine-induced locomotor activity decreased along the course of cocaine injection $(p<0.05$, day 5 vs day $1 ; p<0.01$, day 8 vs day $1 ; F_{(1,12)}=14.22, p<0.01$, interaction between Ro256981cocaine and sham-cocaine, two-way ANOVA) (Fig. $5 H$ ). This behavioral effect of Ro256981 is unlikely to be a general suppressive effect on locomotor activity because chronic intra-NAc perfusion of Ro256981 did not alter the basal locomotor activity in saline-treated rats (Fig. $5 H$ ).

We next examined whether intra-NAc inhibition of NR2Bcontaining NMDARs affected the expression of cocaine-induced locomotor sensitization. Rats with similar intra-NAc surgery were treated with the same $5 \mathrm{~d}$ cocaine procedure. On day 8 , the intraNAc perfusion of Ro256981 was turned on. Upon a challenge injection of cocaine $(12 \mathrm{mg} / \mathrm{kg})$, rats with intra-NAc perfusion of Ro256981 exhibited similar locomotor activities as observed in the sham controls ( $p>0.5, t$ test) (Fig. $5 I)$. Therefore, intra-NAc inhibition of NR2B-containing NMDARs and thus cocaine-generated

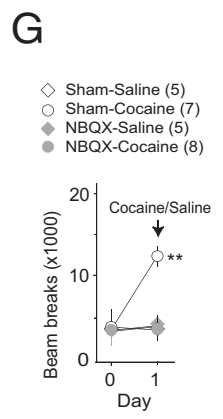

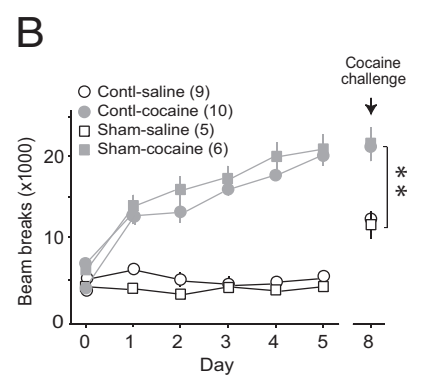
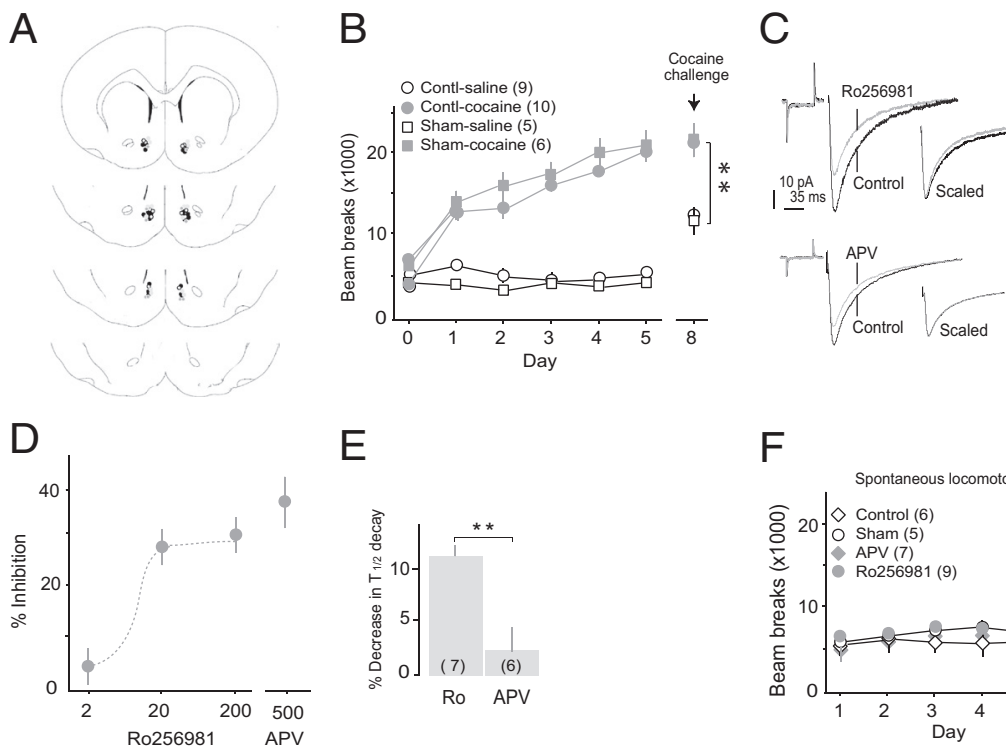

E
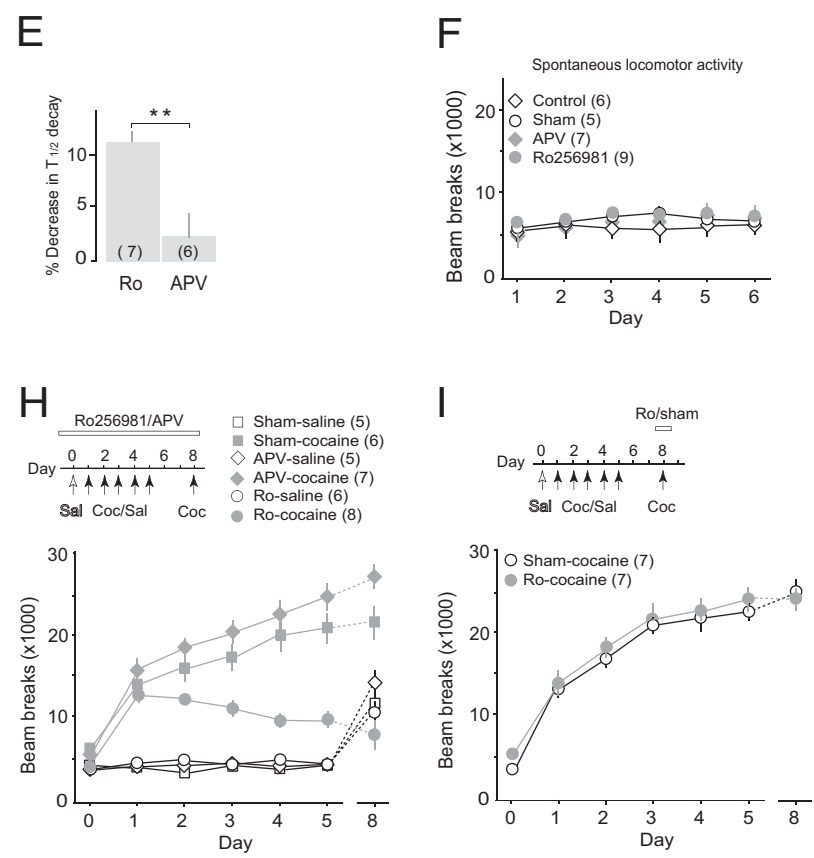

Figure 5. Intra-NAc inhibition of NR2B-containing NMDARs prevented cocaine-induced locomotor sensitization. $A$, Represen-

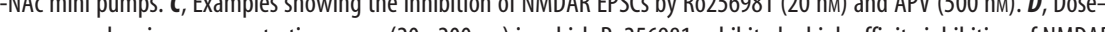
EPSCS. E, Grouped data showing that application of $20 \mathrm{~nm}$ R0256981, but not $500 \mathrm{~nm} \mathrm{APV}$, significantly decreased the $T_{1 / 2}$ (decay kinetics) of NMDAR EPSCs in NAC MSNs. F, Basal/spontaneous locomotor activity was not affected by chronic intra-NAc perfusion of Ro256981 or APV. G, Control for rapid intra-NAc perfusion. With the identical experimental procedure, intra-NAc perfusion of $1 \mu \mathrm{m}$ Q 15 min before cocaine injection prevented cocaine-induced increase in locomotor responses. $\boldsymbol{H}$, Grouped data showing that (b) Ro256981), but not a partial, nonselective inhibition of NAc NMDARs, prevented the development of locomotor sensitization. $I$, Grouped data showing that intra-NAc inhibition of NR2B-containing NMDARs did not affect the expression of cocaine-induced locomotor sensitization. Numbers in parentheses indicate number of cells or number of rats; ${ }^{*} p<0.05 ;{ }^{* *} p<0.01$. Contl, Control; Ro, Ro256981; Sal, saline; Coc, cocaine.

silent synapses disrupted the development, but not the expression, of cocaine-induced locomotor sensitization. Together, these behavioral results suggest that NR2B-signaling, which is enriched in cocaine-generated silent synapses, is importantly implicated in addiction-related behaviors.

\section{Discussion}

Silent synapses are highly efficient plasticity substrates that are primed to undergo both electrophysiological strengthening and anatomical growth to new synaptic activity (Isaac et al., 1999; Philpot and Zukin, 2010). A recent study by Lee and colleagues (2010), in which the authors induce metaplasticity at single synapses, provides compelling evidence that NR2B-containing NMDA receptors favor the induction of long-term potentiation, not long-term depression, an idea that has received considerable 
attention and been hotly debated (Morishita et al., 2007). Our current results, together with previous findings, strongly indicate a silent, synapse-based linear pathway linking cocaine-induced molecular, cellular, and behavioral alterations: (1) exposure to cocaine promotes phosphorylation and activation of CREB and recruitment of pCREB to the NR2B promoter in NAc neurons (Fig. 3) (Carlezon et al., 2005); (2) activation of CREB in NAc neurons increases NR2B protein levels (Fig. 3); (3) exposure to cocaine generates a large number of silent synapses, a process mediated by insertion of new, NR2B-containing NMDARs to likely new synaptic locations (Figs. 1, 4) (Huang et al., 2009); (4) activation of CREB is necessary and sufficient to increase synaptic NR2B and to generate silent synapses in NAc neurons (Figs. 1, 3); and (5) blockade of NR2B-containing NMDARs within the NAc, which preferentially inhibits cocaine-induced newly formed silent synapses (Huang et al., 2009), prevents the development of cocaine-induced locomotor sensitization (Fig. 5). Together, these results suggest a model whereby cocaine activates CREB, which promotes gene transcription of NR2B, leading to enhanced assembly and synaptic incorporation of NR2Bcontaining NMDARs and generation of silent synapses. The increase in silent synapses, in turn, promotes cocaine-induced locomotor sensitization and is likely important to other addiction-related behaviors.

\section{Cocaine-generated silent synapses share core features with nascent synapses in the developing brain}

Silent synapses are typically considered to be immature glutamatergic synapses and as such have an increased capacity for recruiting functional AMPARs to strengthen glutamatergic synaptic transmission (Isaac et al., 1999; Liao et al., 1999; Groc et al., 2006; Kerchner and Nicoll, 2008). Cocaine increases the spine density in NAc MSNs as early as $24 \mathrm{~h}$ after the last cocaine injection (Fig. 4), consistent with previous findings (Kolb et al., 2003; Robinson and Kolb, 2004). This increase is at least partially mediated by de novo generation of silent synapses, as new NR2B-containing NMDARs are inserted into synapses and pharmacological inhibition of NR2B prevents the detection of silent synapses (Huang et al., 2009). However, in a recent study, Zito and colleagues (2009) demonstrated that in organotypic hippocampal slices, silent synapses are not correlated with the age of the spine. Thus, it is possible that some of the silent synapses are generated from preexisting synapses.

Cocaine-induced synapses, like immature synapses, are enriched in the immature, NR2B-containing form of NMDARs (Dingledine et al., 1999; Washbourne et al., 2002; Groc et al., 2006; Lau and Zukin, 2007). This switch in NMDAR subunit composition is functionally important, as NR2B-containing NMDARs have longer decay time constants (Cull-Candy and Leszkiewicz, 2004) and are thus capable of integrating synaptic currents across broader time intervals. In addition to their longer currents, NR2B-containing NMDA receptors carry more $\mathrm{Ca}^{2+}$ current per unit charge (Sobczyk et al., 2005) and are preferentially tethered to the plasticity protein CaMKII (Barria and Malinow, 2005). In a recent paper, Lee and colleagues (2010) demonstrated that the switch to NR2B-containing NMDARs primes synapses to be more easily potentiated. A potential fate of the silent synapses is to mature into fully functional synapses by recruiting new AMPARs. It is conceivable that the cocaineinduced silent synapses have a lowered threshold to undergo subsequent potentiation and thus prime the system for eliciting behavioral sensitization (Yao et al., 2004). If so, new cocaine-specific synaptic connections and even cocaine-specific neural circuits might be formed accordingly.
Cocaine-induced silent synapses are generated in heterogeneous populations of NAc neurons (Fig. 2). This finding is consistent with previous studies that demonstrate a decrease in the AMPAR/NMDAR ratio and increase in spine density in D1 and D2 dopamine receptor-containing MSNs in response to chronic cocaine administration (Lee et al., 2006; Kourrich et al., 2007).

AMPAR/NMDAR ratios are decreased during short-term withdrawal but increased during long-term withdrawal (Kourrich et al., 2007). Findings in the present study suggest that an increase in NR2B and silent synapses contributes to the decrease in AMPAR/NMDAR ratio observed during short-term withdrawal whereas maturation of silent synapses - thus recruiting new AMPARs - contributes to the increase in AMPAR/NMDAR ratio observed during long-term withdrawal (Kourrich et al., 2007).

\section{The role of CREB in cocaine-induced generation of nascent, silent synapses}

CREB plays an essential central role in the formation of new neural circuits during brain development (for review, see Lonze and Ginty, 2002). Activation of CREB increases dendritic spine number, generates silent synapses, and facilitates the strengthening of existing synapses (Figs. 1,4) (Lonze and Ginty, 2002; Marie et al., 2005). dnCREB inhibits synaptogenesis (Lonze et al., 2002). In NAc, CREB is activated by exposure to cocaine or other drugs of abuse (for review, see Carlezon et al., 2005). Upon activation, CREB induces the transcription of genes encoding synaptic vesicle proteins, postsynaptic scaffolding proteins, receptors, neurotrophins, and cell adhesion proteins involved in synaptic and structural plasticity (McClung and Nestler, 2003; Renthal et al., 2009). Activation of CREB promotes the transcription of NR2Bcontaining NMDARs (Fig. 3). NMDAR subunits expressed in the NAc include NR1, NR2A, NR2B, and NR2D (Monyer et al., 1994; Logan et al., 2007). Among these subunits, only the NR1 and NR2B genes contain cAMP response element binding sites, where activated CREB binds and increases NR1 and NR2B mRNA and protein (Klein et al., 1998; Dingledine et al., 1999). Our findings demonstrate that chronic cocaine promotes recruitment of CREB to the NR2B gene promoter, driving NR2B transcription and enhanced translation and assembly of NR2Bcontaining NMDARs. Furthermore, we show that cocaine-induced generation of silent synapses is mediated by CREB. Thus, activation of CREB is an initial step deployed by cocaine to promote generation of new synapses and neurocircuits.

\section{The role of NR2B in locomotor sensitization}

It has long been known that NMDARs are essential for the development of cocaine-induced locomotor sensitization (Wolf, 1998). Our results extend these findings by showing that the NR2B-containing NMDARs are essential for the development of cocaine-induced locomotor sensitization (Fig. 5). Because NR2Bcontaining NMDARs are enriched in cocaine-generated silent synapses (Huang et al., 2009), an attractive scenario is that NR2Bsignaling contributes to cocaine-induced behavioral sensitization. This interpretation is supported by our finding that inhibition of NR2B-containing NMDARs during cocaine administration attenuates locomotor sensitization. In contrast, a subunitnonselective NMDAR antagonist, D-APV, did not block the development of sensitization when applied at concentrations that inhibited a similar portion of total NMDARs as Ro256981 (Fig. 5 ). As the number of silent synapses decreases after several days of withdrawal from cocaine, whereas the locomotor sensitization 
persists, it is conceivable that these premature synapses engage in the formation of new circuits that form the structural basis for locomotor sensitization (Robinson and Berridge, 2000; Huang et al., 2009). This circuitry-based interpretation is in agreement with the view that a circuitry, rather than a specific brain site, mediates the development of locomotor sensitization (for review, see Wolf, 1998). Alternatively, it is also possible that the overall intra-NAc NR2B-signaling, rather than the new synaptic connections, is required for the development of locomotor sensitization. Thus, the insertion of NR2B-containing NMDARs in silent synapses can be regarded as an overall enhancement of the NAc NR2B-signaling, which, in turn, may trigger NR2B-specific neuronal modifications that are important for the development of locomotor sensitization.

A likely cellular consequence of cocaine-generated silent synapses is the extension of the functionally active state (i.e., upstate) of NAc neurons. Synaptic NMDARs preferentially contribute to the duration of the upstates of NAc MSNs because of their relatively slow decay kinetics, which has been demonstrated both computationally (Wolf et al., 2005) and experimentally (Huang et al., 2007). Thus, an overall increase in postsynaptic NMDARs may prolong the duration of individual upstates in NAc neurons. This effect can be further enhanced by NR2B-containing receptors, which exhibit even slower decay kinetics, and are upregulated by cocaine (Huang et al., 2009). A second cellular consequence is the enhancement of NR2B-CaMKII signaling. NR2B-containing NMDARs possess higher binding affinity for CaMKII than NR2A-containing receptors, and thus result in stronger stimulation of the NMDAR/CaMKII-signaling cascade upon activation (Strack and Colbran, 1998). The activity of CaMKII in NAc is upregulated following exposure to cocaine (Anderson et al., 2008), and inhibiting the NAc CaMKII attenuates cocaine-induced locomotor sensitization (Pierce et al., 1998) and drug-seeking behaviors (Anderson et al., 2008).

The behavioral and functional consequences of cocaine and amphetamine administration are very similar (Wolf, 1998). However, the effect on NR2B expression and the effect of the NR2B antagonist Ro256981 on the expression of drug-induced locomotor sensitization are seemingly different between cocaine and amphetamine (Fig. 5) (Huang et al., 2009; Mao et al., 2009). Prolonged withdrawal from amphetamine causes a reduction in total NR2B protein levels and high concentrations of Ro256981 increased locomotor sensitization after $14 \mathrm{~d}$ of withdrawal. In addition to the potential pharmacological and physiological difference between cocaine and amphetamine, different experimental design (time course) and pharmacological manipulations (concentrations of Ro256981) may account for the differences in the results.

This study suggests that newly formed synapses contribute to the development of cocaine-induced locomotor sensitization, thus potentially providing a molecular angle to manipulate the neural bases underlying sensitized emotional and motivational state associated with addiction.

\section{References}

Andersen SL, Arvanitogiannis A, Pliakas AM, LeBlanc C, Carlezon WA Jr (2002) Altered responsiveness to cocaine in rats exposed to methylphenidate during development. Nat Neurosci 5:13-14.

Anderson SM, Famous KR, Sadri-Vakili G, Kumaresan V, Schmidt HD, Bass CE, Terwilliger EF, Cha JH, Pierce RC (2008) CaMKII: a biochemical bridge linking accumbens dopamine and glutamate systems in cocaine seeking. Nat Neurosci 11:344-353.
Apicella P, Scarnati E, Ljungberg T, Schultz W (1992) Neuronal activity in monkey striatum related to the expectation of predictable environmental events. J Neurophysiol 68:945-960.

Barria A, Malinow R (2005) NMDA receptor subunit composition controls synaptic plasticity by regulating binding to CaMKII. Neuron 48:289-301.

Brami-Cherrier K, Valjent E, Hervé D, Darragh J, Corvol JC, Pages C, Arthur SJ, Simon AJ, Girault JA, Caboche J (2005) Parsing molecular and behavioral effects of cocaine in mitogen- and stress-activated protein kinase-1-deficient mice. J Neurosci 25:11444-11454.

Burns LH, Everitt BJ, Kelley AE, Robbins TW (1994) Glutamate-dopamine interactions in the ventral striatum: role in locomotor activity and responding with conditioned reinforcement. Psychopharmacology (Berl) 115:516-528.

Carlezon WA Jr, Duman RS, Nestler EJ (2005) The many faces of CREB. Trends Neurosci 28:436-445.

Cull-Candy SG, Leszkiewicz DN (2004) Role of distinct NMDA receptor subtypes at central synapses. Sci STKE 2004:re16.

David HN, Sissaoui K, Abraini JH (2004) Modulation of the locomotor responses induced by D1-like and D2-like dopamine receptor agonists and D-amphetamine by NMDA and non-NMDA glutamate receptor agonists and antagonists in the core of the rat nucleus accumbens. Neuropharmacology 46:179-191.

Dingledine R, Borges K, Bowie D, Traynelis SF (1999) The glutamate receptor ion channels. Pharmacol Rev 51:7-61.

Dong Y, Green T, Saal D, Marie H, Neve R, Nestler EJ, Malenka RC (2006) CREB modulates excitability of nucleus accumbens neurons. Nat Neurosci 9:475-477.

Durand GM, Kovalchuk Y, Konnerth A (1996) Long-term potentiation and functional synapse induction in developing hippocampus. Nature 381:71-75.

Gong S, Zheng C, Doughty ML, Losos K, Didkovsky N, Schambra UB, Nowak NJ, Joyner A, Leblanc G, Hatten ME, Heintz N (2003) A gene expression atlas of the central nervous system based on bacterial artificial chromosomes. Nature 425:917-925.

Groc L, Gustafsson B, Hanse E (2006) AMPA signalling in nascent glutamatergic synapses: there and not there! Trends Neurosci 29:132-139.

Hooks MS, Jones GH, Hemby SE, Justice JB Jr (1993) Environmental and pharmacological sensitization: effects of repeated administration of systemic or intra-nucleus accumbens cocaine. Psychopharmacology (Berl) 111:109-116.

Hsia AY, Malenka RC, Nicoll RA (1998) Development of excitatory circuitry in the hippocampus. J Neurophysiol 79:2013-2024.

Huang YH, Lin Y, Brown TE, Han MH, Saal DB, Neve RL, Zukin RS, Sorg BA, Nestler EJ, Malenka RC, Dong Y (2007) CREB modulates the functional output of nucleus accumbens neurons: a critical role of N-methyl-Daspartate glutamate (NMDA) receptors. J Biol Chem 283:2751-2760; [Erratum 283:11860].

Huang YH, Lin Y, Mu P, Lee BR, Brown TE, Wayman G, Marie H, Liu W, Yan Z, Sorg BA, Schlüter OM, Zukin RS, Dong Y (2009) In vivo cocaine experience generates silent synapses. Neuron 63:40-47.

Hyman SE, Malenka RC, Nestler EJ (2006) Neural mechanisms of addiction: the role of reward-related learning and memory. Annu Rev Neurosci 29:565-598.

Isaac JT, Nicoll RA, Malenka RC (1995) Evidence for silent synapses: implications for the expression of LTP. Neuron 15:427-434.

Isaac JT, Nicoll RA, Malenka RC (1999) Silent glutamatergic synapses in the mammalian brain. Can J Physiol Pharmacol 77:735-737.

Kaddis FG, Wallace LJ, Uretsky NJ (1993) AMPA/kainate antagonists in the nucleus accumbens inhibit locomotor stimulatory response to cocaine and dopamine agonists. Pharmacol Biochem Behav 46:703-708.

Kafetzopoulos E (1986) Effects of amphetamine and apomorphine on locomotor activity after kainic acid lesion of the nucleus accumbens septi in the rat. Psychopharmacology (Berl) 88:271-274.

Kalivas PW (2004) Glutamate systems in cocaine addiction. Curr Opin Pharmacol 4:23-29.

Kalivas PW (2007) Neurobiology of cocaine addiction: implications for new pharmacotherapy. Am J Addict 16:71-78.

Kalivas PW, Lalumiere RT, Knackstedt L, Shen H (2009) Glutamate transmission in addiction. Neuropharmacology 56 [Suppl 1]:169-173.

Kauer JA, Malenka RC (2007) Synaptic plasticity and addiction. Nat Rev Neurosci 8:844-858. 
Kerchner GA, Nicoll RA (2008) Silent synapses and the emergence of a postsynaptic mechanism for LTP. Nat Rev Neurosci 9:813-825.

Kim J, Dittgen T, Nimmerjahn A, Waters J, Pawlak V, Helmchen F, Schlesinger S, Seeburg PH, Osten P (2004) Sindbis vector SINrep(nsP2S726): a tool for rapid heterologous expression with attenuated cytotoxicity in neurons. J Neurosci Methods 133:81-90.

Klein M, Pieri I, Uhlmann F, Pfizenmaier K, Eisel U (1998) Cloning and characterization of promoter and $5^{\prime}$-UTR of the NMDA receptor subunit epsilon 2: evidence for alternative splicing of $5^{\prime}$-non-coding exon. Gene 208:259-269.

Kolb B, Gorny G, Li Y, Samaha AN, Robinson TE (2003) Amphetamine or cocaine limits the ability of later experience to promote structural plasticity in the neocortex and nucleus accumbens. Proc Natl Acad Sci U S A 100:10523-10528.

Koob GF, Volkow ND (2010) Neurocircuitry of addiction. Neuropsychopharmacology 35:217-238.

Kourrich S, Rothwell PE, Klug JR, Thomas MJ (2007) Cocaine experience controls bidirectional synaptic plasticity in the nucleus accumbens. J Neurosci 27:7921-7928.

Kullmann DM (1994) Amplitude fluctuations of dual-component EPSCs in hippocampal pyramidal cells: implications for long-term potentiation. Neuron 12:1111-1120.

Kullmann DM, Erdemli G, Asztély F (1996) LTP of AMPA and NMDA receptor-mediated signals: evidence for presynaptic expression and extrasynaptic glutamate spill-over. Neuron 17:461-474.

Kumar A, Choi KH, Renthal W, Tsankova NM, Theobald DE, Truong HT, Russo SJ, Laplant Q, Sasaki TS, Whistler KN, Neve RL, Self DW, Nestler EJ (2005) Chromatin remodeling is a key mechanism underlying cocaineinduced plasticity in striatum. Neuron 48:303-314.

Lau CG, Zukin RS (2007) NMDA receptor trafficking in synaptic plasticity and neuropsychiatric disorders. Nat Rev Neurosci 8:413-426.

Lee KW, Kim Y, Kim AM, Helmin K, Nairn AC, Greengard P (2006) Cocaine-induced dendritic spine formation in D1 and D2 dopamine receptor-containing medium spiny neurons in nucleus accumbens. Proc Natl Acad Sci U S A 103:3399-3404.

Lee MC, Yasuda R, Ehlers MD (2010) Metaplasticity at single glutamatergic synapses. Neuron 66:859-870.

Le Moine C, Bloch B (1995) D1 and D2 dopamine receptor gene expression in the rat striatum: sensitive cRNA probes demonstrate prominent segregation of D1 and D2 mRNAs in distinct neuronal populations of the dorsal and ventral striatum. J Comp Neurol 355:418-426.

Li Y, Hu XT, Berney TG, Vartanian AJ, Stine CD, Wolf ME, White FJ (1999) Both glutamate receptor antagonists and prefrontal cortex lesions prevent induction of cocaine sensitization and associated neuroadaptations. Synapse 34:169-180.

Liao D, Zhang X, O’Brien R, Ehlers MD, Huganir RL (1999) Regulation of morphological postsynaptic silent synapses in developing hippocampal neurons. Nat Neurosci 2:37-43.

Livak KJ, Schmittgen TD (2001) Analysis of relative gene expression data using real-time quantitative PCR and the 2(-Delta Delta C(T)) method. Methods 25:402-408.

Logan SM, Partridge JG, Matta JA, Buonanno A, Vicini S (2007) Longlasting NMDA receptor-mediated EPSCs in mouse striatal medium spiny neurons. J Neurophysiol 98:2693-2704.

Lonze BE, Ginty DD (2002) Function and regulation of CREB family transcription factors in the nervous system. Neuron 35:605-623.

Lonze BE, Riccio A, Cohen S, Ginty DD (2002) Apoptosis, axonal growth defects, and degeneration of peripheral neurons in mice lacking CREB. Neuron 34:371-385.

Losi G, Prybylowski K, Fu Z, Luo JH, Vicini S (2002) Silent synapses in developing cerebellar granule neurons. J Neurophysiol 87:1263-1270.

Mao LM, Wang W, Chu XP, Zhang GC, Liu XY, Yang YJ, Haines M, Papasian CJ, Fibuch EE, Buch S, Chen JG, Wang JQ (2009) Stability of surface NMDA receptors controls synaptic and behavioral adaptations to amphetamine. Nat Neurosci 12:602-610.

Marie H, Morishita W, Yu X, Calakos N, Malenka RC (2005) Generation of silent synapses by acute in vivo expression of CaMKIV and CREB. Neuron 45:741-752.

Mattson BJ, Bossert JM, Simmons DE, Nozaki N, Nagarkar D, Kreuter JD, Hope BT (2005) Cocaine-induced CREB phosphorylation in nucleus accumbens of cocaine-sensitized rats is enabled by enhanced activation of extracellular signal-related kinase, but not protein kinase A. J Neurochem 95:1481-1494.

Maze I, Covington HE 3rd, Dietz DM, LaPlant Q, Renthal W, Russo SJ, Mechanic M, Mouzon E, Neve RL, Haggarty SJ, Ren Y, Sampath SC, Hurd YL, Greengard P, Tarakhovsky A, Schaefer A, Nestler EJ (2010) Essential role of the histone methyltransferase G9a in cocaine-induced plasticity. Science 327:213-216.

McClung CA, Nestler EJ (2003) Regulation of gene expression and cocaine reward by CREB and DeltaFosB. Nat Neurosci 6:1208-1215.

Monyer H, Burnashev N, Laurie DJ, Sakmann B, Seeburg PH (1994) Developmental and regional expression in the rat brain and functional properties of four NMDA receptors. Neuron 12:529-540.

Morishita W, Lu W, Smith GB, Nicoll RA, Bear MF, Malenka RC (2007) Activation of NR2B-containing NMDA receptors is not required for NMDA receptor-dependent long-term depression. Neuropharmacology 52:71-76.

O'Donnell P, Grace AA (1993) Dopaminergic modulation of dye coupling between neurons in the core and shell regions of the nucleus accumbens. J Neurosci 13:3456-3471.

Philpot BD, Zukin RS (2010) Synapse-specific metaplasticity: to be silenced is not to silence $2 \mathrm{~B}$. Neuron 66:814-816.

Pickard L, Noël J, Henley JM, Collingridge GL, Molnar E (2000) Developmental changes in synaptic AMPA and NMDA receptor distribution and AMPA receptor subunit composition in living hippocampal neurons. J Neurosci 20:7922-7931.

Pierce RC, Quick EA, Reeder DC, Morgan ZR, Kalivas PW (1998) Calciummediated second messengers modulate the expression of behavioral sensitization to cocaine. J Pharmacol Exp Ther 286:1171-1176.

Rani CS, Qiang M, Ticku MK (2005) Potential role of cAMP response element-binding protein in ethanol-induced N-methyl-D-aspartate receptor $2 \mathrm{~B}$ subunit gene transcription in fetal mouse cortical cells. Mol Pharmacol 67:2126-2136.

Renthal W, Kumar A, Xiao G, Wilkinson M, Covington HE 3rd, Maze I, Sikder D, Robison AJ, LaPlant Q, Dietz DM, Russo SJ, Vialou V, Chakravarty S, Kodadek TJ, Stack A, Kabbaj M, Nestler EJ (2009) Genomewide analysis of chromatin regulation by cocaine reveals a role for sirtuins. Neuron 62:335-348.

Robinson TE, Berridge KC (2000) The psychology and neurobiology of addiction: an incentive-sensitization view. Addiction 95 [Suppl 2]:S91S117.

Robinson TE, Berridge KC (2001) Incentive-sensitization and addiction. Addiction 96:103-114.

Robinson TE, Berridge KC (2008) Review. The incentive sensitization theory of addiction: some current issues. Philos Trans R Soc Lond B Biol Sci 363:3137-3146.

Robinson TE, Kolb B (2004) Structural plasticity associated with exposure to drugs of abuse. Neuropharmacology 47 [Suppl 1]:33-46.

Russo SJ, Wilkinson MB, Mazei-Robison MS, Dietz DM, Maze I, Krishnan V, Renthal W, Graham A, Birnbaum SG, Green TA, Robison B, Lesselyong A, Perrotti LI, Bolaños CA, Kumar A, Clark MS, Neumaier JF, Neve RL, Bhakar AL, Barker PA, Nestler EJ (2009) Nuclear factor kappa B signaling regulates neuronal morphology and cocaine reward. J Neurosci 29:3529-3537.

Schultz W, Apicella P, Scarnati E, Ljungberg T (1992) Neuronal activity in monkey ventral striatum related to the expectation of reward. J Neurosci 12:4595-4610.

Shen H, Sesack SR, Toda S, Kalivas PW (2008) Automated quantification of dendritic spine density and spine head diameter in medium spiny neurons of the nucleus accumbens. Brain Struct Funct 213:149-157.

Sobczyk A, Scheuss V, Svoboda K (2005) NMDA receptor subunitdependent $[\mathrm{Ca} 2+]$ signaling in individual hippocampal dendritic spines. J Neurosci 25:6037-6046.

Strack S, Colbran RJ (1998) Autophosphorylation-dependent targeting of calcium/ calmodulin-dependent protein kinase II by the NR2B subunit of the N-methyl-D-aspartate receptor. J Biol Chem 273:20689-20692.

Thomas MJ, Kalivas PW, Shaham Y (2008) Neuroplasticity in the mesolimbic dopamine system and cocaine addiction. Br J Pharmacol 154:327-342.

Tirelli E, Laviola G, Adriani W (2003) Ontogenesis of behavioral sensitization and conditioned place preference induced by psychostimulants in laboratory rodents. Neurosci Biobehav Rev 27:163-178.

Todtenkopf MS, Carreiras T, Melloni RH, Stellar JR (2002) The dorsome- 
dial shell of the nucleus accumbens facilitates cocaine-induced locomotor activity during the induction of behavioral sensitization. Behav Brain Res 131:9-16.

Vanderschuren LJ, Kalivas PW (2000) Alterations in dopaminergic and glutamatergic transmission in the induction and expression of behavioral sensitization: a critical review of preclinical studies. Psychopharmacology (Berl) 151:99-120.

Washbourne P, Bennett JE, McAllister AK (2002) Rapid recruitment of NMDA receptor transport packets to nascent synapses. Nat Neurosci 5:751-759.

Williams SR, Mitchell SJ (2008) Direct measurement of somatic voltage clamp errors in central neurons. Nat Neurosci 11:790-798.

Wolf JA, Moyer JT, Lazarewicz MT, Contreras D, Benoit-Marand M, O’Donnell P, Finkel LH (2005) NMDA/AMPA ratio impacts state transitions and entrainment to oscillations in a computational model of the nucleus accumbens medium spiny projection neuron. J Neurosci 25:9080-9095.
Wolf ME (1998) The role of excitatory amino acids in behavioral sensitization to psychomotor stimulants. Prog Neurobiol 54:679-720.

Wolf ME, Ferrario CR (2010) AMPA receptor plasticity in the nucleus accumbens after repeated exposure to cocaine. Neurosci Biobehav Rev 35:185-211.

Yao WD, Gainetdinov RR, Arbuckle MI, Sotnikova TD, Cyr M, Beaulieu JM, Torres GE, Grant SG, Caron MG (2004) Identification of PSD-95 as a regulator of dopamine-mediated synaptic and behavioral plasticity. Neuron 41:625-638.

Zhang Y, Schlussman SD, Ho A, Kreek MJ (2003) Effect of chronic "binge cocaine" on basal levels and cocaine-induced increases of dopamine in the caudate putamen and nucleus accumbens of C57BL/6J and 129/J mice. Synapse 50:191-199.

Zito K, Scheuss V, Knott G, Hill T, Svoboda K (2009) Rapid functional maturation of nascent dendritic spines. Neuron 61:247-258. 